\title{
Immunological manipulation of growth
}

\author{
BY J. M. PELL \\ Department of Cellular Physiology, Babraham Institute, Cambridge CB2 4AT
}

Growth rate and final body size are determined by intrinsic and extrinsic factors which can be summarized as the animal's inherited gene pool and the subsequent environmental and nutritional conditions that will interact with the inherited genotype resulting in the observed phenotype. All these are communicated via the endocrine system, and it is possible to increase growth rate and lean tissue deposition towards genetic potential by exogenous administration of key hormones. However, this approach has several disadvantages; public perception of hormone treatment is poor and the preparation of long-lasting formulations for protein hormones can be problematical, even though pharmaceutical companies are addressing this (Pell \& Aston, 1995). The possibility of changing hormone activity rather than altering the amount of hormone has been considered, therefore, as an attractive alternative for the improvement of growth efficiency.

\section{ANTIBODIES CAN INHIBIT, MIMIC OR POTENTIATE HORMONE ACTIVITY}

The classical view of antibody function is of neutralization of protein activity and subsequent clearance of the protein via the reticulo-endothelial system. Several reports during the 1970s cast doubt over this straightforward concept; it was demonstrated that the activities of bradykinin (Goodfriend et al. 1970) and epidermal growth factor (Shechter et al. 1979) were enhanced rather than inhibited by antibodies. Subsequent studies have shown also that the activities of many peptide hormones can be potentiated: insulin (Gray et al. 1985), human (h) growth hormone (GH; Holder et al. 1985), thyroid-stimulating hormone (Holder et al. 1987), bovine (b) GH (Pell et al. 1989), follicle-stimulating hormone (Glencross et al. 1993), tumour necrosis factor (Rathjen et al. 1992), insulin-like growth factor-I (IGF-1; Stewart et al. 1993) and GH-releasing factor (GRF; Pell \& James, 1995). Further, immuno-enhancement has been demonstrated both in vivo and in vitro (Pell \& James, 1995). It is theoretically possible, therefore, to design strategies to increase overall signalling of key pathways, either by neutralizing the activity of inhibitory factors or by potentiating the activity of stimulatory factors.

Antibodies can also be used as hormone mimics. The antigen binding site of a primary antibody (paratope) can be imagined to be the equivalent of a mirror image of the epitope of the antigen to which it binds. If secondary antibodies (anti-idiotypic antibodies) bind to the paratope then, theoretically, they will be structural mimics of the original antigen and, therefore, could function in a similar manner to the original antigen.

The present article will review the potential of using an immunological approach to improve growth rate and lean tissue mass in animals. As GH is essential for normal growth and exogenous GH can improve the efficiency of lean tissue deposition, most research on the immunomodulation of hormone activity has centred around the GH axis. This will be used, therefore, as a model to describe antibody-mediated manipulation of hormone function in growing animals. In brief, GH is synthesized in and secreted from the pituitary gland; processes which are regulated primarily by GRF (stimulates GH secretion) and somatostatin (inhibits $\mathrm{GH}$ secretion). GH interacts with its receptor and either has direct actions on tissues or stimulates the synthesis of the polypeptide growth factor, IGF-I, which 
is synthesized ubiquitously and mediates many of the anabolic actions of GH. However, tissue mRNA levels suggest that the liver is a major source of IGF-I synthesis and, in large part, is responsible for circulating IGF-I; such endocrine IGF-I may have a role in the coordination of tissue anabolism and act in concert with tissue-derived growth factor (Daughaday \& Rotwein, 1989).

\section{ANTIBODY DESIGN AND IMMUNIZATION STRATEGIES}

Antibodies can be present in an animal via either passive or active immunization; both offer some benefits for regulated modulation of protein hormone function. Passive immunization is the administration of exogenous antibodies which have been derived from another animal, whereas active immunization is the generation of endogenous antibody by direct exposure of the host animal to small amounts of antigen. Active immunization, therefore, involves the injection of minute quantities of antigen $(\mu \mathrm{g})$ which probably will not induce an independent physiological response and will be degraded rapidly. Antigen will only need to be administered as prime and boost immunizations in much the same manner as techniques used to confer disease resistance; this is likely, therefore, to be a more acceptable technological approach to the general public than that of hormone administration. Additionally, active immunization is likely to be long-lasting (months) compared with the short-term (days) effects of most protein hormones. In the case of passive immunization, exogenous antibodies will be cleared by the recipient animal and, therefore, will need to be administered regularly; antibody clearance will vary from a few hours to 3 weeks depending on whether or not antibodies are prepared from the same species. It is also likely that the recipient animal will raise antibodies against the administered antibodies if not self-species. The overall titre against the original antigen is important; obviously high titres are desirable and are more likely to be achieved via a successful active immunization than by passive immunization and subsequent dilution of antibody in vivo.

Protein function has been investigated using several different forms of antibodies. The most specific mechanistic data on hormone function can be generated using monoclonal antibodies (MAb) binding to a defined epitope; however, at present murine MAb are of little practical use for animal production purposes. Most commonly, immunization has been performed with intact hormone, leading to the production of polyclonal antibodies which have the potential to recognize many sites on the antigen, depending on its structure. Such antisera will usually be inhibitory because the 'peppering' of the surface of the hormone with high-affinity antibodies will prevent receptor interaction, even if no antibody directly interacts with the receptor binding region of the hormone. Antibody-mediated enhancement of hormone activity has been observed using both MAb and polyclonal antibody preparations. The interpretation of these observations depends on the several hypotheses currently under consideration to explain the phenomenon, and will be considered in more detail (see p. 624). However, if site-directed antibodies are required, it is possible to immunize with specific peptide regions of a protein, generating polyclonal antibodies but of restricted specificity to the intact protein; obviously these will only yield antibodies recognizing linear epitopes, whereas MAb usually bind to conformation epitopes consisting of discontinuous regions of the hormone.

\section{INHIBITION OF SOMATOSTATIN ACTIVITY}

In theory, immuno-neutralization of somatostatin should stimulate $\mathrm{GH}$ secretion from the pituitary gland, resulting in increased endogenous GH concentrations in blood. The initial 
studies, in growing lambs, demonstrated dramatic increases in weight gain (Spencer et al. $1985 a, b)$. Unfortunately, numerous subsequent studies have either refuted or supported these findings; no real consensus has emerged. Westbrook et al. (1993) have generated interesting data by immunizing pregnant ewes against somatostatin during the latter half of gestation and observing the subsequent performance of lambs during the immediate postpartum period. Milk yield at 2, 4 and 6 weeks post partum was significantly increased by 20-30\%. Interestingly, the mean birth weight of lambs from immunized ewes was significantly greater than that for the control ewes and their growth rate was also increased significantly. The authors suggest that the anti-somatostatin-immunized animals were able to partition nutrients more efficiently towards the uterus and mammary gland. Subsequent studies have suggested that the presence of anti-somatostatin antibodies or an alternative bioactive factor in milk induced increased appetite and efficiency of nutrient utilization in lambs (Westbrook \& McDowell, 1995).

The reasons for the discrepant results of many anti-somatostatin studies are unclear, but might lie in consideration of the actions of somatostatin itself, which are wide-ranging and involve complex feedback mechanisms. A further possibility is experimental variation in achieving consistent high antibody titre and affinity for somatostatin. Current data suggest that, in quantitative terms, somatostatin function may be more focused towards gastrointestinal function than to its inhibition of $\mathrm{GH}$ secretion; a common feature of many anti-somatostatin studies is an increased efficiency of feed utilization (Elsaesser \& Drath, 1995).

\section{ANTIBODIES AS HORMONE MIMICS}

The potential of anti-idiotypes (secondary antibodies against primary antibodies) to act as protein mimics, and therefore function in a similar manner to the original antigen, has been explored in rodents using $\mathrm{GH}$ as the primary antigen. Anti-idiotypic antibodies were able to specifically inhibit $\mathrm{GH}$ binding to various tissues and, when given passively to hypophysectomized rats, were able to stimulate an increase in body-weight gain in an analogous fashion to GH (Gardner et al. 1990). The responsiveness of the rats to the antiidiotypic antibodies was much less than that to GH itself. One obvious explanation for this apparent insensitivity might be that only a particular set of anti-GH antibodies can act as an immunogen: those which recognize the receptor-binding site(s) of GH. These might not be generated with a sufficiently high titre and affinity. Since the crystal structure of GH binding to its receptor has been determined (de Vos et al. 1992), it might be possible to identify peptide regions of GH which are within the binding domain and could yield an immune response restricted to that part of the molecule. These antibodies could then be used to generate the anti-idiotypes; in practice, however, it is difficult to produce antipeptide antibodies with a high affinity for the molecule from which the peptide has been selected.

\section{POTENTIATION OF HORMONE ACTIVITY}

Holder et al. (1985) were the first to recognize the potential of increasing hormone activity for the improvement of growth efficiency. However, their initial observations were in hypopituitary rodents and, therefore, correction of a growth lesion was being investigated rather than the improvement of normal growth. Pell et al. (1989) provided evidence that this phenomenon could be extended to normal animals of production relevance. MAb raised against ovine GH (and which cross-react with $b G H$ ) enhanced the galactopoietic 
actions of exogenous bGH in lactating ewes. Of more interest, however, were observations on the diabetogenic action of $\mathrm{GH}$ in growing lambs (treatment with exogenous bGH inhibits insulin-induced decreases in blood glucose concentrations). Such a decrease in glucose concentration was almost completely abolished in lambs pre-treated with exogenous bGH which had been complexed to MAb OA11. Interestingly, the insulininduced decrease in blood glucose concentrations was also significantly inhibited in lambs which had been administered MAb OA11 alone. Taken together these data imply that MAb cannot only potentiate the activity of exogenous hormone but also of endogenous hormone. The latter finding has clear significance for the improvement of growth efficiency; if animals could generate similar endogenous antibodies which could interact with endogenous hormone, then signalling via a particular hormone pathway could be enhanced. Of key importance in developing such an antibody response is the characterization of the properties of the original MAb which confer its enhancing activity so that suitable antigens could be designed. It is probable that these properties are either the site of binding to the antigen or the affinity of the antibody for the antigen.

At present, the mechanism of action of enhancing antibodies is unclear, although several have been proposed (see Pell \& Aston, 1995); however, the enhancement of peptide hormone activity now appears to be a widespread phenomenon. In addition, even simple chemical cross-linking of $\mathrm{GH}$, either to albumin or even to itself, apparently can potentiate GH activity (Holder et al. 1989). Thus, any proposed mechanism for hormone potentiation must be able to incorporate the diverse structure of the hormones potentiated, the varied nature of the antibodies used (MAb or polyclonal) and random $\mathrm{NH}_{2}$-mediated crosslinking; alternatively several mechanisms may exist. First, when the hormone-antibody complex is formed, an antibody-induced conformational change could occur in the hormone which increases the affinity of the hormone for its receptor. Such a phenomenon has been reported for GH when bound to a specific MAb (Mazza \& Retegui, 1989). Second, when a hormone can bind to several different receptor sub-types in vivo or to a binding protein, the presence of a site-directed antibody could restrict access of the hormone to one receptor and, therefore, increase availability to another receptor. Since some hormones, e.g. GRF, have only one known receptor, this 'restriction hypothesis' is probably not possible in all cases. A third hypothesis is simply that potentiating antibodies protect the hormone from degradation and decrease the clearance of bioactive hormone. Most peptide hormones are rapidly degraded in vivo, their half-lives being between 10 and $20 \mathrm{~min}$. The GH-enhancing anti-peptide antibodies reported by Aston et al. (1991) may protect a proteolytically-sensitive region of GH from degradation. Wang et al. (1992) have shown that accumulation of GH in tissues is greater in hypophysectomized rats treated with GH complexed to an enhancing antibody than when the hormone is given alone, suggesting that the antibody alters the pharmacokinetics and biodistribution of GH. Pharmacokinetic studies have demonstrated that insulin-enhancing antibodies act via a 'depot' or slowrelease mechanism, indicating a prolonged half-life (Gray et al. 1985). Stewart et al. (1993) have shown that circulating IGF-I concentrations are significantly increased when IGF-I is pre-complexed to an enhancing antibody, implying that the peptide is protected from degradation. Indeed, the hypothesis that the bioavailability and, therefore, bioactivity of peptide and protein hormones may be modified by the formation of complexes in the pericellular environment is gaining increasing support, and specific antibodies may provide such a tier of regulation. A fourth suggestion is that some increase in receptor 'efficiency' occurs. Such a theory would help to account for the observations that enhancement can occur when antibody concentration is limited (Pell et al. 1989). For example, a decrease in hormone-receptor internalization rate could occur when hormone is bound to antibody, so 
that contact between hormone and receptor is prolonged. Indeed, there is some evidence that enhancing MAb might increase total hormone occupancy of receptor without changing receptor number (Massart et al. 1993).

Evidence can be found to support all the previously mentioned hypotheses, although some emerge as more likely than others. It is appropriate, therefore, to consider the more recent findings on antibody enhancement in relation to growth regulation.

\section{Immuno-enhancement and inhibition of growth hormone-releasing factor activity in vivo and in vitro}

hGRF is a forty- or forty-four-residue peptide, which, unlike $\mathrm{GH}$, is bioactive in many species. Full activity may be obtained with only residues 1-29 and this contains the receptor-binding domain of the peptide; the function of residues $30-44$ is unknown but may be related to the stability of the peptide. We (Pell \& James, 1995) examined the effects of site-directed anti-peptide antibodies raised against the $\mathrm{N}$ - and $\mathrm{C}$-terminal regions of the peptide on the ability of GRF to stimulate $\mathrm{GH}$ release in vivo in sheep and in vitro using primary cultures of sheep pituitary cells. Fig. 1 shows circulating GH concentrations in sheep after a single dose of GRF, anti-1-14 or anti-35-44 immunoglobulin (Ig), or a preincubated mixture of Ig and GRF. GRF alone stimulated GH concentrations to a maximum of about $25 \mathrm{ng} / \mathrm{ml}$ within $30 \mathrm{~min}$, followed by a decrease by $60 \mathrm{~min}$; a biphasic response was observed in many animals with an additional smaller GH peak between 60 and 120 min. Anti-1-14 Ig alone had no effect on GH concentrations, whereas the complex of anti-1-14 antibodies and GRF completely abolished the GRF-stimulated GH release. Anti35-44 Ig pre-complexed to GRF induced a further stimulation of GH concentrations compared with GRF alone, partly due to an increase in the initial peak and also to an enhanced secondary peak. Interestingly, anti-35-44 Ig alone stimulated an increase in GH concentrations to almost the same extent as GRF alone, implying that the antibody could interact with endogenous GRF or had some effect on the GRF receptor. Concurrent studies in vitro have demonstrated that the anti-35-44 antibodies can enhance GRF in cultured pituitary cells, and also that the antibody does not interact directly with the GRF receptor (Pell \& James, 1995).
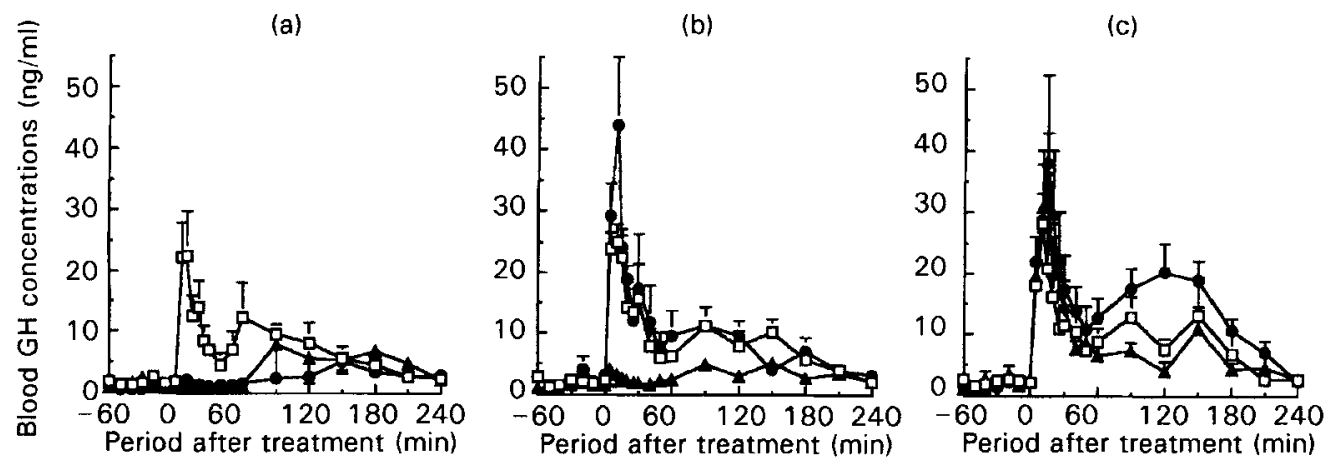

Fig. 1. Blood growth hormone (GH) concentrations in sheep after treatment with GH-releasing factor (GRF; $1 \mu \mathrm{g} / \mathrm{kg}$ intravenously) and anti-GRF anti-peptide immunoglobulin (IG). Sheep were administered a single dose of GRF alone $(\square)$, anti-peptide immunoglobulin alone $(\mathbf{\Delta})$, or a pre-incubated mixture of GRF and anti-peptide $\operatorname{Ig}(\boldsymbol{O})$ at time zero. (a), Anti-1-14 Ig; (b), anti-31-44 Ig; (c), anti-35-44 Ig. Values are means with their standard errors represented by vertical bars for five sheep per group. (From Pell \& James, 1995.) 
These studies are compatible with three of the possible mechanisms for antibody enhancement of hormone activity listed previously. The key significance of this study is in the potentiation of hormone activity in vitro as well as in vivo, allowing consideration of changes in hormone-receptor interaction. The affinity and activity of GRF for its receptor can be increased by modification of its sequence to improve the amphiphilic properties of the peptide. For example, substitution of an alanine for glycine at residue 15 increases and extends the stability of the $\alpha$-helical structure and creates a greater lipophilic face for membrane receptor binding (Kaiser \& Kezdy, 1984; Clore et al. 1986; Campbell et al. 1991). It is possible that antibodies directed against the C-terminal end of GRF might stabilize the $\alpha$-helical structure of the $\mathrm{NH}_{2}$-terminal, thus increasing the affinity of the hormone for its receptor. In addition, the hormone-antibody complex could induce a decrease in receptor internalization rate compared with hormone alone, and this could in some manner lead to an increase in signalling. One hypothesis accounting for hormone enhancement in vivo is the protection of hormone degradation by antibodies. GRF is rapidly degraded in vivo, both by enzymic and chemical pathways, its half-life being between 10 and $20 \mathrm{~min}$ (Su et al. 1991; Boulanger et al. 1992). Modification of GRF sequence to reduce degradation can induce increases in activity as GRF-stimulated GH release of threefold in vitro (rat pituitary cell culture) and elevenfold in vivo (Campbell et al. 1994). Since the increase in activity was far greater in vivo, where hormone clearance is known to be important, these data demonstrate the scope for increasing the activity of certain peptide hormones in vivo merely by protection from proteolytic degradation. The function of the C-terminal fifteen residues of GRF is unknown, but it has been proposed that they increase the instability of the molecule since hGRF(1-32)-OH is more stable than hGRF(1-44)- $\mathrm{NH}_{2}$ (Campbell et al. 1994); it is possible, therefore, that antibody binding to the C-terminal may increase GRF stability.

\section{Potentiation of growth hormone activity by active immunization with a synthetic peptide region of growth hormone}

Possible regions of $\mathrm{GH}$ to which antibodies might bind were identified by prediction of peptide sequences likely to be on the surface of the molecule and with high mobility (Aston et al. 1991); a panel of peptides were tested in hypopituitary mice for possible potentiation of GH activity and one was selected for further investigation in growing lambs (Pell \& Aston, 1991). Subsequently multiple-pin peptide synthesis techniques (Geysen et al. 1984) were used. Lambs were immunized with a synthetic peptide derived from the loop region joining helices 3 and 4 and their subsequent carcass composition determined after 10 weeks exposure to auto-antibodies against the peptide in the presence and absence of exogenous GH. Final body composition is shown in Fig. 2. Lambs treated with exogenous GH alone exhibited increased carcass protein and water content with simultaneous decreased fat content. However, lambs exposed only to anti-peptide antibodies only had increased lean tissue mass without concomitant decreased fat content. Those lambs immunized against the peptide fragment of $\mathrm{GH}$ and administered $\mathrm{GH}$ did not have a further increase in lean tissue content compared with GH or peptide immunization alone but exhibited an intermediate fat content. These data, therefore, suggest that it is possible to auto-immunize animals and generate antibodies which might interact with endogenous hormones. Further, they also indicate that not all the properties of the original hormone are potentiated. This finding supports the 'restriction' hypothesis of antibody potentiation, i.e. that it is possible to direct hormone activity towards a particular receptor sub-type where receptor heterogeneity 
(a)

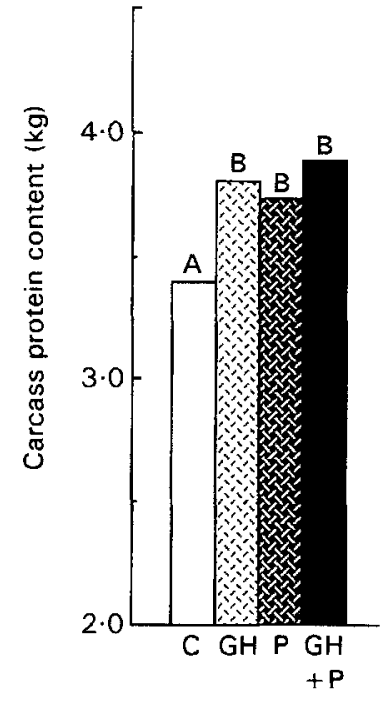

(b)

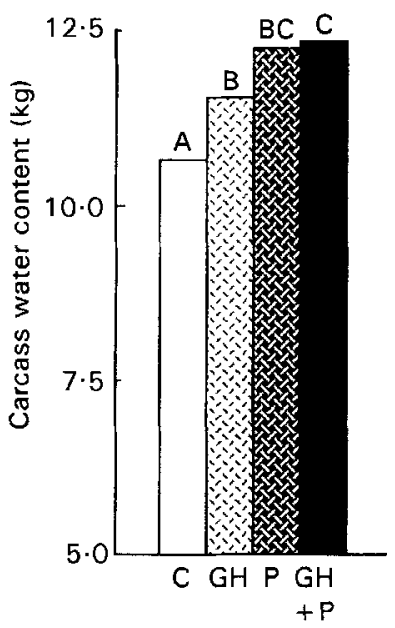

(c)

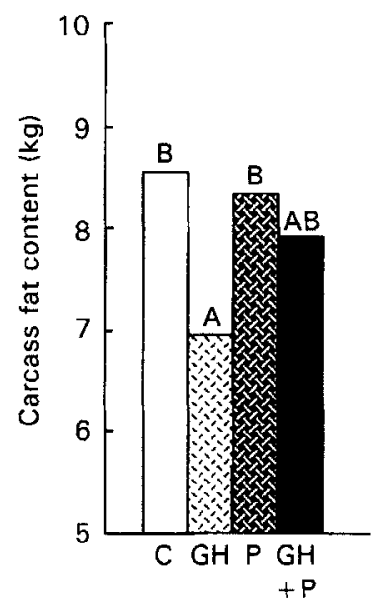

Fig. 2. (a) Carcass protein, (b) water and (c) fat for control (C; $\square$ ), growth hormone-treated (GH; 图), peptideimmunized (P; ) and GH + P-treated ( $\mathbf{0}$ ) lambs. A, B, C Means within each histogram not sharing a common superscript letter were significantly different $(P<0.05)$. SED $(n 10):$ protein $0.14 \mathrm{~kg}$, water $0.41 \mathrm{~kg}$, fat $0.59 \mathrm{~kg}$. The $\mathrm{GH} \times \mathrm{P}$ treatment effects were not statistically significant $(P>0 \cdot 1)$. (From Pell \& Aston, 1991.)

exists, although, with the observation that hormone potentiation can occur where only a single receptor exists, it is difficult to reconcile this as the only hypothesis.

\section{Antibody enhancement of insulin-like growth factor-I activity; analogy with naturally-occurring binding proteins}

IGF-I is a multi-functional peptide which stimulates cellular proliferation and differentiation and is essential for normal growth and development (Liu et al. 1993; Powell-Braxton et al. 1993). The potency of IGF-I is such that very little peptide is found in the free form in vivo; instead, it is bound to one of a family of at least six highly-specific IGF-binding proteins (IGFBP) which moderate IGF-I activity and are synthesized by individual tissues in a highly regulated manner (Rechler, 1994). Even though the precise functions of each IGFBP are not characterized fully, IGFBP probably exert specific functions such as the targeting and transport of IGF-I to its receptors. Since IGF-I is secreted via the constitutive pathway, no conventional tissue stores exist and, therefore, a further important function of the IGFBP is to maintain a reservoir of IGF-I. This can be attributed in particular to IGFBP-3 which binds in excess of $90 \%$ of circulating IGF-I. IGFBP-3 may exist as either a binary complex with IGF-I or, after association with an additional protein (the acid-labile subunit; ALS), may form a ternary complex that is large enough to be confined to the circulation (Baxter \& Martin, 1989). Certain IGFBP (-1, -2, -3 and -5) modulate IGF-I activity by switching their normal inhibitory action to one of enhancement; precise mechanisms for such dual action are not fully elucidated but involve a reduction in the affinity of the IGFBP for IGF-I, closer to that of the IGF type 1 receptor (for comprehensive review, see Jones \& Clemmons, 1995). Thus, a very sophisticated system 
(a)

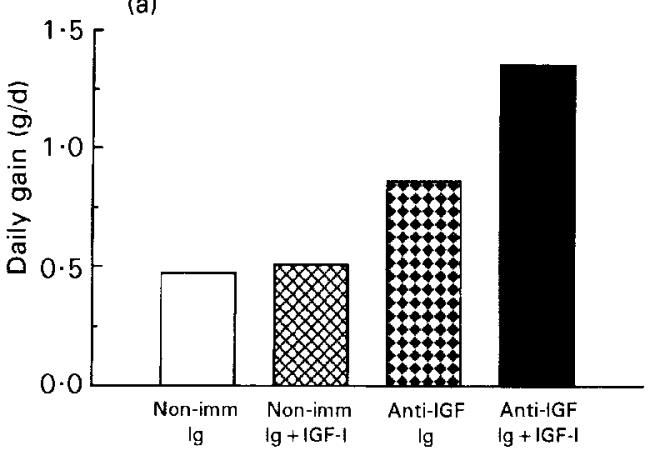

(b)

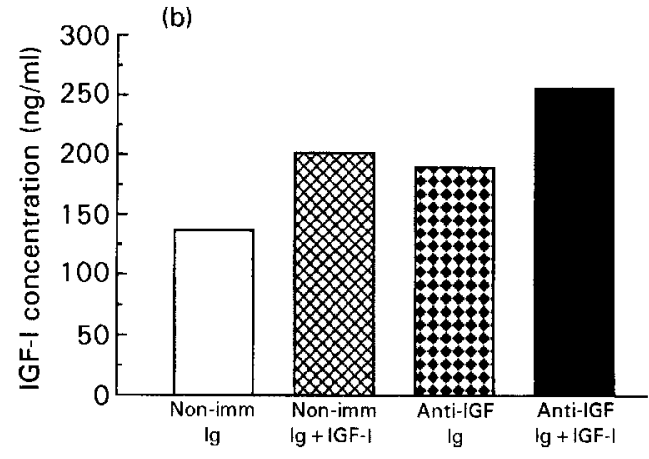

Fig. 3. (a) Daily gain and (b) serum insulin-like growth factor (IGF)-I concentrations in dwarf rats treated with nonimmune immunoglobulin (non-imm Ig; $\square$ ), non-imm Ig + IGF-I (100 $\mu \mathrm{g} / \mathrm{d}$; ), anti-IGF-I immunoglobulin (anti-IGF-I Ig; 7 ) or anti-IGF-I Ig + IGF-I ( $)$. Data were analysed by two-way ANOVA with anti-IGF-I Ig and IGF-I as main effects ( $n$ 6 per group). Anti-IGF-I Ig significantly increased daily gain $(P=0.035)$ when considered as a main effect. (a) SED $0.38 \mathrm{~g} / \mathrm{d}$, (b) SED $34 \mathrm{ng} / \mathrm{ml}$. IGF-I concentrations were increased by IGF-I $(P=0.011)$ and anti-IGF-I Ig $(P=0.038)$. (From Stewart et al. 1993.)

appears to have evolved to maintain the circulating reservoir of IGF and control its delivery, availability and targeting to tissues.

Antibodies have a similar molecular mass to that for the IGF-I-IGFBP-3-ALS ternary complex $(150 \mathrm{kDa})$ and, therefore, may provide a model for further elucidation of the function of the IGF ternary complex and its importance for IGF-I stability and bioavailability. We therefore investigated the actions of a specific anti-IGF-I antibody (raised in sheep against hIGF-I) and demonstrated that the antibody enhanced IGF-I activity in vivo (Stewart et al. 1993). This is illustrated in Fig. 3 which shows the weight gain and circulating IGF-I concentrations for dwarf rats (low GH synthesis and secretion rate; Charlton et al. 1988). Dwarf rats treated with an IGF-I-antibody complex exhibited increased weight gain and serum IGF-I concentrations compared with those treated with IGF-I alone. Interestingly, those administered anti-IGF-I Ig alone also tended to have increased weight gain and circulating IGF-I levels compared with rats given control Ig only, indicating that the Ig might interact with endogenous IGF-I. Since the antibody had a modest affinity for IGF-I, equivalent to that of the IGF type 1 receptor, we suggested that the antiserum might protect IGF-I from degradation whilst maintaining it in a bioavailable form. The aim of a further investigation (Hill et al. 1997) was to test that hypothesis by determining the plasma clearance and tissue distribution of tracer IGF-I in the presence of the enhancing anti-IGF-I Ig or non-immune Ig; the anti-IGF-I Ig did indeed reduce IGF-I metabolic clearance rate and degradation (Fig. 4(a and b)). These data support the suggestion that enhancing antibodies can change the kinetics of peptide hormone metabolism in an analogous manner to one of the key putative functions of IGFBP.

\section{CONCLUSIONS}

The data presented in the present review suggest that it is possible to change peptide hormone activity using antibodies either as inhibitory or enhancing binding proteins; additionally, antibodies can be designed as structural and functional mimics of specific peptide motifs. These antibodies can either be produced in one animal and administered to another, or be induced in the animal of interest. The latter approach is probably better for the improvement of growth efficiency. However, such active immunizations will probably 

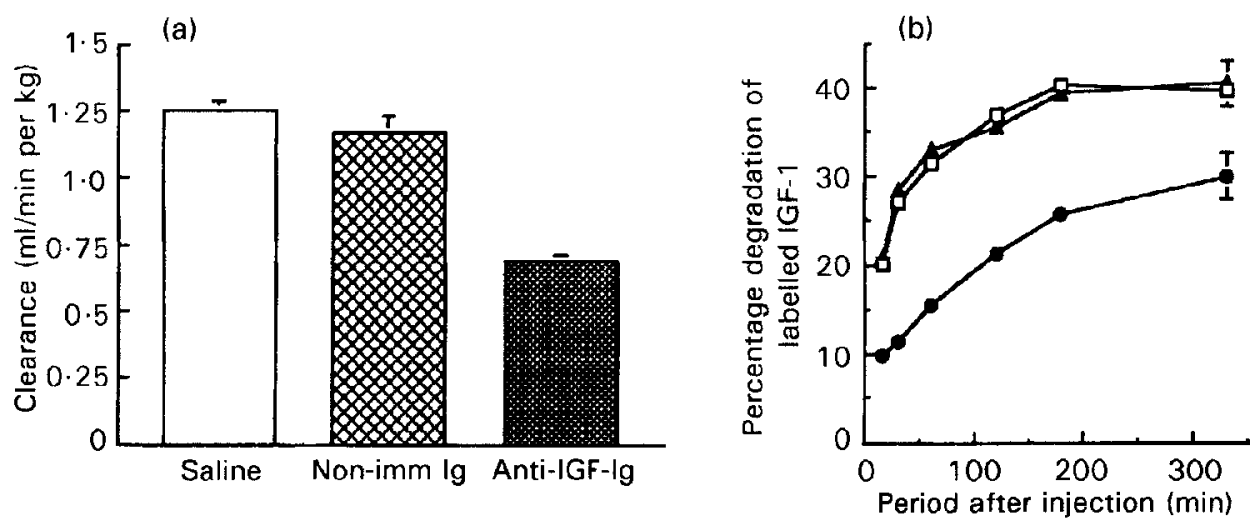

Fig. 4. (a) Calculated clearance of TCA-precipitable radioactivity in dwarf rats following intravenous injection with ${ }^{125}$ I-labelled insulin-like growth factor (IGF)-I. Values are means with their standard errors represented by vertical bars for six rats per treatment group. (b) Mean percentage degradation of labelled IGF-I in plasma of dwarf rats, calculated as TCA-soluble radioactivity (counts/min; $\mathrm{cpm}$ ) as a percentage of total radioactivity (cpm) for each time point. Values are means for six animals per group: saline $(9 \mathrm{~g} \mathrm{NaCl} / 1 ; \boldsymbol{\Delta})$, non-immune immunoglobulin (non-imm Ig; $\square$ ), anti-IGF-1 immunoglobulin (Ig; $)$; the standard errors, represented by vertical bars, are shown for the final time point only for clarity.

induce counter-regulatory mechanisms, which probably explains the variable responsiveness observed. It is, therefore, important that reaction to immunization with self-proteins (or peptides derived from self-proteins) is understood more clearly.

\section{REFERENCES}

Aston, R., Rathjen, D. A., Holder, A. T., Bender, V., Trigg, T. E., Cowan, K., Edwards, J. A. \& Cowden, W. B. (1991). Antigenic structure of bovine growth hormone: location of a growth enhancing region. Molecular Immunology 28, 41-50.

Baxter, R. C. \& Martin, J. L. (1989). Structure of the Mr 140,000 growth hormone-dependent insulin-like growth factor binding protein complex: determination by reconstitution and affinity labeling. Proceedings of the National Academy of Sciences USA 86, 6878-6902.

Boulanger, L., Roughly, P. \& Gaudreau, P. (1992). Catabolism of rat growth hormone-releasing factor(1-29) amide in rat serum and liver. Peptides 13, 681-689.

Campbell, R. M., Lee, Y., Rivier, J., Heimer, L. P., Felix, A. M. \& Mowles, T. F. (1991). GRF analogs and fragments: correlation between receptor binding, activity and structure. Peptides 12, 569-574.

Campbell, R. M., Stricker, P., Miller, R., Bonger, J., Liu, W., Lambros, T., Ahmad, M., Felix, A. M. \& Heimer, E. $P$. (1994). Enhanced stability and potency of novel growth hormone-releasing factor (GRF) analogues derived from rodent and human GRF sequences. Peptides 15, 489-495.

Charlton, H. M., Clark, R. G., Robinson, I. C. A. F., Porter Goff, A. E., Cos, B. S., Bugnon, C. \& Bloch, B. A. (1988). Growth hormone-deficient dwarfism in the rat: a new mutation. Journal of Endocrinology 119, 51-58.

Clore, G. M., Martin, S. R. \& Gronenborn, A. M. (1986). Solution structure of human growth hormone releasing factor. Combined use of circular dichroism and nuclear magnetic resonance spectroscopy. Journal of Molecular Biology 191, 553-561.

Daughaday, W. H. \& Rotwein, P. (1989). Insulin-like growth factor-I and factor-II-peptide, messenger ribonucleic-acid and gene structures, serum, and tissue concentrations. Endocrine Reviews 10, 68-91.

De Vos, A. M., Ultsch, M. \& Kossiakoff, A. A. (1992). Human growth hormone and extracellular domain of its receptor: crystal structure of the complex. Science 255, 306-312.

Elsaesser, G. \& Drath, S. (1995). The potential of immunoneutralization against somatostatin for improving pig performance. Livestock Production Science 42, 255-263.

Gardner, M. J., Morrison, C. J., Stevenson, L. Q. \& Flint, D. J. (1990). Production of an anti-idiotypic antisera to rat $\mathrm{GH}$ antibodies capable of binding to $\mathrm{GH}$ receptors and increasing body weight gain in hypophysectomised rats. Journal of Endocrinology 125, 55-59.

Geysen, H. M., Meloen, R. H. \& Barteling, S. J. (1984). Use of peptide-synthesis to probe viral-antigens for epitopes to a resolution of a single amino-acid. Proceedings of the National Academy of Sciences USA 81, $3998-4002$. 
Glencross, R. G., Lovell, R. D. \& Holder, A. T. (1993). Monoclonal antibody enhancement of FSH-induced uterine growth in Snell dwarf mice. Journal of Endocrinology 136, R5-R7.

Goodfriend, T. L., Webster, M. E. \& McGuire, J. S. (1970). Complex effects of antibodies to polypeptide hormones. Journal of Clinical Endocrinology 30, 565-572.

Gray, R. S., Cowan, P., di Mario, J., Elson, R. A., Clarke, B. F. \& Duncan, L. J. P. (1985). Influence of insulin antibodies on pharmacokinetics and bioavailability of recombinant human and highly purified beef insulins in insulin dependent diabetics. British Medical Journal 290, 1687-1692.

Hill, R. A., Flick-Smith, H. C., Dye, S. \& Pell, J. M. (1997). Actions of an IGF-I-enhancing antibody on IGF-I pharmacokinetics and tissue distribution: increased IGF-I bioavailability. Joumal of Endocrinology 152, 123-130.

Holder, A. T., Aston, R., Preece, M. \& Ivanyi, J. (1985). Monoclonal antibody mediated enhancement of growth hormone activity in vivo. Journal of Endocrinology 107, R9-R12.

Holder, A. T., Aston, R., Rest, J. R., Hill, D. J., Patel, N. \& Ivanyi, J. (1987). Monoclonal antibodies can enhance the biological activity of thyrotropin. Endocrinology 120, 567-673.

Holder, A. T., Morrell, D. J., Lovell, R. D. \& Aston, R. (1989). Growth hormone activity is enhanced when covalently linked to large protein. Joumal of Endocrinology 123, Suppl. 126.

Jones, J. I. \& Clemmons, D. R. (1995). Insulin-like growth factors and their binding proteins: biological actions. Endocrine Reviews 16, 3-34.

Kaiser, E. T. \& Kezdy, F. J. (1984). Amphiphilic secondary structure: design of peptide hormones. Science 223, 249-255.

Liu, J.-P., Baker, J., Perkins, A. S., Robertson, E. J. \& Efstratiadis, A. (1993). Mice carrying null mutations of the genes encoding insulin-like growth factor I (Igf-l) and type 1 IGF receptor $($ Igflr). Cell 75, 59-72.

Massart, S., Maiter, D., Portetelle, D., Adam, E., Renaville, R. \& Ketelslegers, J.-M. (1993). Monoclonal antibodies to bovine growth hormone $(\mathrm{GH})$ potentiate hormonal activity in vivo by enhancing $\mathrm{GH}$ binding to hepatic somatogenic membranes. Journal of Endocrinology 139, 383-393.

Mazza, M. M. \& Retegui, L. A. (1989). Monoclonal antibodies to human growth hormone induce an allosteric conformational change in the antigen. Immunology 67, 148-153.

Pell, J. M. \& Aston, R. (1991). Active immunisation with a synthetic peptide region of growth hormone: increased lean tissue growth. Journal of Endocrinology 131, R1-R4.

Pell, J. M. \& Aston, R. (1995). Principles of immunomodulation. Livestock Production Science 42, 123-133.

Pell, J. M. \& James, S. (1995). Immuno-enhancement and -inhibition of GH-releasing factor by site-directed antipeptide antibodies in vivo and in vitro. Journal of Endocrinology 146, 535-541.

Pell, J. M., Johnsson, I. D., Pullar, R. A., Morrell, D. J., Hart, I. C., Holder, A. T. \& Aston, R. (1989). Potentiation of growth hormone activity in sheep using monoclonal antibodies. Journal of Endocrinology 120, R15-R18.

Powell-Braxton, L., Hollingshead, P., Warburton, C., Dowd, M., Pitts-Meek, S., Dalton, D., Gillett, N. \& Stewart, T. A. (1993). IGF-I is required for normal embryonic growth in mice. Genes and Development 7, 2609-2717.

Rathjen, D. A., Murphy, L. J. \& Aston, R. (1992). Selective enhancement of the tumour necrotic activity of TNFalpha with monoclonal antibody. British Journal of Cancer 65, 852-856.

Rechler, M. M. (1994). Insulin-like growth factor binding proteins. Vitamins and Hormones 47, 1-1 14.

Shechter, Y., Hernaez, L., Schlessinger, J. \& Cuatrecasas, P. (1979). Local aggregation of hormone-receptor complexes is required for activation by epidermal growth factor. Nature $278,835-838$.

Spencer, G. S. G., Garssen, G. J. \& Hart, I. C. (1985a). A novel approach to growth promotion using autoimmunization against somatostatin. I. Effects on growth and hormone levels in lambs. Livestock Production Science 10, 25--37.

Spencer, G. S. G., Garssen, G. J. \& Hart, I. C. (1985b). A novel approach to growth promotion using autoimmunization against somatostatin. II. Effects on appetite, carcass composition and food utilization in the lamb. Livestock Production Science 10, 469-477.

Stewart, C. E. H., Bates, P. C., Calder, T. A., Woodall, S. M. \& Pell, J. M. (1993). Potentiation of insulin-like growth factor-I (IGF-I) activity by an antibody: supportive evidence for enhancement of IGF-I bioavailability in vivo by IGF binding proteins. Endocrinology 133, 1462-1465.

Su, C.-M., Jensen, L. R., Heimer, E. P., Felix, A. M., Pan, Y.-C. E. \& Mowles, T. F. (1991). In vitro stability of growth hormone releasing (GRF) factor analogs in porcine plasma. Hormone and Metabolic Research 23, 1521.

Wang, B. S., Lumanglas, A. L., Szewczyk, E., McWilliams, W., Loullis, C. C. \& Hart, I. C. (1992). A proposed mechanism of action of a growth hormone-specific monoclonal antibody in the enhancement of hormonal activity. Molecular Immunology 29, 313-317.

Westbrook, S. L., Chandler, K. D. \& McDowell, G. H. (1993). Immunization of pregnant ewes against somatotropin release inhibiting factor increases growth in twin lambs. Australian Journal of Agricultural Research 44, 229-238.

Westbrook, S. L. \& McDowell, G. H. (1995). Passively acquired antibodies to somatostatin alter the secretion of gastric acid and enhance the growth of sucking piglets. Proceedings of the Nutrition Society of Australia 19 , 183. 